\title{
Apical ballooning (Takotsubo) syndrome in the setting of chronic alcohol-induced hyponatremia
}

\author{
Yehualashet Bekele Hailemariam*1, Olufolahan Carrena ${ }^{1}$, Derek Eshun ${ }^{1}$, Henry E. Okafor ${ }^{1,2}$ \\ ${ }^{1}$ Department of Internal Medicine, Meharry Medical College, Nashville, TN, United States \\ ${ }^{2}$ Division of Cardiology, Vanderbilt University Medical Center, Nashville, TN, United States
}

Received: July 24, 2018

DOI: $10.5430 /$ crim.v5n $4 \mathrm{p} 10$
Accepted: September 20, 2018 Online Published: September 26, 2018

URL: https://doi.org/10.5430/crim.v5n4p10

\begin{abstract}
Takotsubo cardiomyopathy is also known as stress induced cardiomyopathy and transient left ventricular apical ballooning syndrome. There have been few case reports where hyponatremia was implicated as a trigger for stress-induced cardiomyopathy. We report the unusual case of a 79-year-old African American woman without any discernible recent stressors who presented atypically with generalized fatigue and was found to have severe hyponatremia (from chronic alcohol use and thiazide diuretics) and significantly elevated Troponin. Her echocardiogram and cardiac catheterization revealed typical features of apical ballooning syndrome.
\end{abstract}

Key Words: Stress cardiomyopathy, Hyponatremia, Chronic alcohol use

\section{INTRODUCTION}

Stress-induced cardiomyopathy (Takotsubo cardiomyopathy) is described as acute, reversible apical ventricular dysfunction and apical akinesis in the absence of obstructive coronary artery disease (CAD). ${ }^{[1]}$ The condition was first described in Japan in 1991 and is commonly seen in elderly women with a history of psycho-social stressors. Typical presentation may include chest pain, ST segment elevation electrocardiogram (EKG) changes and elevated cardiac enzymes, mimicking acute ST elevation myocardial infarction. ${ }^{[2]}$ The pathophysiology is thought to be secondary to increased catecholamine release. ${ }^{[3,4]}$ Although psychosocial stressors are commonly implicated as a cause, there have been a few case reports where hyponatremia ${ }^{[5,6]}$ and alcohol withdrawal ${ }^{[7,8]}$ were also reported as triggers for Takotsubo cardiomyopathy.

\section{Case presentation}

We report the case of a 79-year-old African American female who presented to the emergency department (ED) with a complaint of generalized body weakness of about 10 hours duration. She reported that she lived alone and added that the night before her presentation, she was sitting on a couch watching TV while drinking some beer and getting ready to have her dinner. She however found out that she was unable to get up from her couch due to bilateral leg weakness and in the absence of immediate help, had to spend the whole night (about 10 hours) on the couch. In the morning, she was able to crawl to her phone and call her sister who called the emergency medical services (EMS) to take her to the emergency department. There was no associated chest pain, shortness of breath, cough, palpitations or dizziness. Patient denied any recent stressful experiences or trauma. Her medical history

\footnotetext{
*Correspondence: Yehualashet Bekele Hailemariam; Email: Yehualab@yahoo.com; Address: Department of Internal Medicine, Meharry Medical College, Vanderbilt University Medical Center, Nashville, TN, United States.
} 
was significant for chronic alcohol use disorder and hypertension, which was well controlled with Amlodipine and Hydrochlorothiazide-Lisinopril combination. Her last drink was reportedly about 10 hours prior to presentation.

On physical examination, vital signs were stable with a temperature of $98.1^{\circ} \mathrm{F}$, blood pressure was $108 / 75 \mathrm{mmHg}$, heart rate was 73 beats per minute and respiratory rate was 16 per minute with an oxygen saturation of 100 percent on room air. She was alert and oriented to time, place and person with no jugular venous distension. Her lungs were clear, and had no abnormal heart sounds, no peripheral edema and the strength in all her extremities was found to be $5 / 5$. Initial work up in the ER was significant for an initial sodium level of $129 \mathrm{mEq} / \mathrm{L}$ and later, $122 \mathrm{mEq} / \mathrm{L}$ on repeat check. Serum bicarbonate level was $14 \mathrm{mEq} / \mathrm{L}$, indicating metabolic acidosis, which was likely related to rhabdomyolysis as her serum creatinine kinase (CK) level was elevated at $5,347 \mathrm{U} / \mathrm{L}$, which was likely precipitated by the period of prolonged immobilization and subsequent tedious crawling to reach her phone. Her blood urea nitrogen and creatinine levels were $23 \mathrm{mg} / \mathrm{dl}$ and $1.18 \mathrm{mg} / \mathrm{dl}$ respectively, which was consistent with her known baseline. Her liver enzymes were elevated with an aspartate aminotransferase level of $134 \mathrm{U} / \mathrm{L}$ and an alanine aminotransferase level of $18 \mathrm{U} / \mathrm{L}$ which indicated a greater than 2:1 ratio consistent with alcoholic liver disease. Her alcohol level on admission was found to be $95 \mathrm{mg} / \mathrm{dl}$. Her initial troponin I level was elevated at $11.7 \mathrm{ng} / \mathrm{ml}$, with the MB fraction of Creatinine Kinase (CKMB) being $87.2 \mathrm{ng} / \mathrm{ml}$ and Serum CK of 5,347 U/L. Her troponin peaked at $12.6 \mathrm{ng} / \mathrm{ml}(0.0-0056)$ and trended down to $1.3 \mathrm{ng} / \mathrm{ml}$ over the next three days and initial EKG showed sinus bradycardia with non-specificT-wave abnormalities without ST segment elevation or depression. Her Brain Natriuretic Peptide level was also elevated at $624 \mathrm{pg} / \mathrm{ml}$. Urinalysis was only remarkable for $3+$ blood but without RBCs and consistent with myoglobinuria from rhabdomyolysis. The thyroid stimulating hormone (TSH) level was normal at $2.09 \mathrm{U} / \mathrm{ml}$. Her other labs at initial presentation are listed in Table 1. Left heart catheterization showed normal coronary vessels without obstructive coronary artery disease while the 2D-Echocardiogram showed left ventricular (LV) apical akinesis with LV Ejection fraction (EF) of 30-35 percent consistent with apical ballooning syndrome, part of the echo image is shown in Figure 1. Hyponatremia was corrected with fluid restriction and the patient was counseled on the need for proper diet and the dangers of excessive alcohol consumption. Hydrochlorothiazide was replaced with a Bblocker.

Subsequent 2D echocardiogram after about 4 months of treatment showed improved EF of 50\%-55\% with normalization

Published by Sciedu Press of the prior regional wall motion abnormalities.

Table 1. Other lab values at presentation

\begin{tabular}{ll}
\hline Lab Name & Lab Value \\
\hline WBC $^{*}$ & $9.7 / \mathrm{mm}^{3}$ \\
$\mathrm{HGB}^{\#}$ & $11 \mathrm{mg} / \mathrm{dl}$ \\
$\mathrm{HCT}^{\dagger}$ & $34 \%$ \\
Platelete Count & $241,000 / \mathrm{mm}^{3}$ \\
Serum Potassium & $5 \mathrm{MEQ} / \mathrm{L}$ \\
Serum Chloride & $97 \mathrm{MEQ} / \mathrm{L}$ \\
Glucose & $102 \mathrm{mg} / \mathrm{dl}$ \\
\hline
\end{tabular}

Note. ${ }^{*}$ WBC: White blood count; ${ }^{\#}$ HGB: Hemoglobin; ${ }^{\dagger}$ HCT: Hematocrit

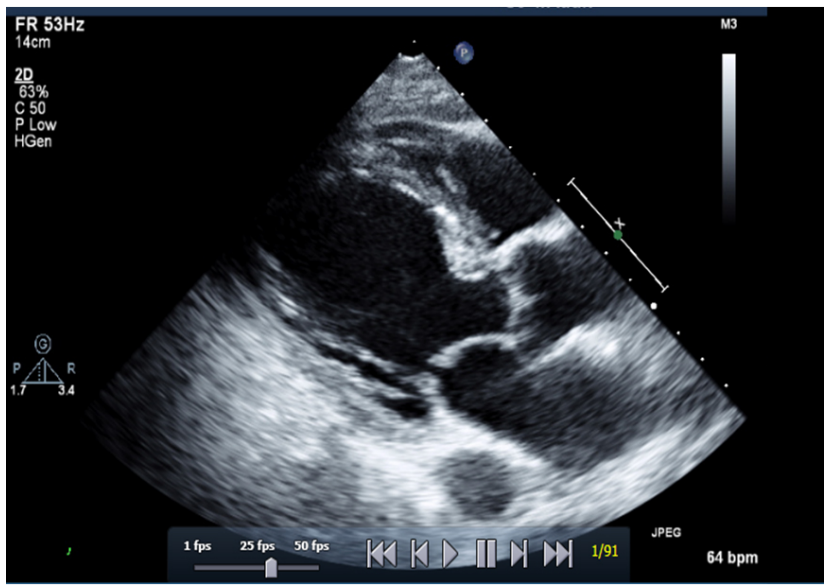

Figure 1. Parasternal long axis view

\section{Discussion}

Significantly elevated troponin peaking at $12.6 \mathrm{ng} / \mathrm{ml}$ without angiographic evidence of CAD on left heart catheterization combined with typical echocardiographic findings of severe LV apical hypokinesis/akinesis with preserved contractility of the basal walls highly favors diagnosis of Takotsubo cardiomyopathy in our patient.

Psychosocial and physical stressors are commonly incriminated as precipitants for Takotsubo cardiomyopathy by way of inducing excess catecholamines, however, our patient denied any recent history of stress or acute distress. Literature search revealed about six other case reports which showed severe hyponatremia as a trigger for stress-induced cardiomyopathy. The causes of hyponatremia in those cases were SIADH, diuretics, psychogenic polydipsia and in one of the cases, the cause of hyponatremia was unknown as shown in Table 2. In all cases the threshold at which stress cardiomyopathy occurred differed however the sodium level was always less than or equal to $120 \mathrm{mEq} / \mathrm{L}$. Our patient is alcoholic and was on thiazide diuretics, both of which could have contributed to induce hyponatremia via effect of beer 
potomania and natriuresis from diuretics respectively. Our patient's sodium level was initially noted to be $129 \mathrm{mEq} / \mathrm{L}$ and on confirmatory repeat test, dropped to $122 \mathrm{mEq} / \mathrm{L}$. Her serum osmolality was $275 \mathrm{mmol} / \mathrm{kg}$ (Nomal range for adults: 285-295), which is consistent with hypo-osmolar hyponatremia and in this case, indicative of alcohol-induced hyponatremia. The mechanism by which hyponatremia causes catecholamine excess and or stress cardiomyopathy is unknown. ${ }^{[3,9]}$ On the other hand, there are case reports that acute alcohol withdrawal can cause stress-induced cardiomyopathy, ${ }^{[6,8]}$ however in our patient, there was no evidence of alcohol withdrawal as her last drink was only 10 hours earlier and her vital signs were stable while her blood alcohol level at presentation was $95 \mathrm{mg} / \mathrm{dl}$. This unique case further supports the evidence that moderate to severe hyponatremia independent of psychosocial or traumatic stressors could trigger the left ventricular apical ballooning syndrome. Further studies are needed to elucidate the mechanism(s) by which this is effected.
Table 2. Previously reported cases of hyponatremia induced stress cardiomyopathy

\begin{tabular}{llllll}
\hline & Age & Sex & Na (meq/L) & Causes of hyponatremia & Ref. \\
\hline 1 & 69 & F & 109 & SIADH & 9 \\
2 & 63 & F & 110 & Not known & 10 \\
3 & 76 & F & 120 & Diuretics & 11 \\
4 & 57 & F & 111 & SIADH & 11 \\
5 & 82 & M & 105 & SIADH/Vomiting & 12 \\
6 & 41 & M & 113 & Psychogenic Polydipsia & 13 \\
\hline
\end{tabular}

Note. SIADH: Syndrome of Anti-diuretic Hormone

\section{Conclusion}

Clinicians should recognize that hyponatremia secondary to Beer Potomania can trigger stress-induced cardiomyopathy as seen in our patient.

\section{CONFlicts OF InTEREST Disclosure}

The authors declare no conflicts of interest.

\section{REFERENCES}

[1] Tsuchihashi K, Ueshima K, Uchida T, et al. Transient left ventricular apical ballooning without coronary artery stenosis: a novel heart syndrome mimicking acute myocardial infarction. Journal of the American College of Cardiology. 2001; 38(1): 11-18. https : //doi.org/10.1016/S0735-1097(01)01316-X

[2] Abe Y, Kondo M, Matsuoka R, et al. Assessment of clinical features in transient left ventricular apical ballooning. Journal of the American College of Cardiology. 2003; 41(5): 737-742. https: //doi.org/10.1016/S0735-1097(02) 02925-X

[3] Paur H, Wright PT, Sikkel MB, et al. High Levels of Circulating Epinephrine Trigger Apical Cardiodepression in a 2-Adrenergic Receptor/Gi-Dependent Manner: A New Model of Takotsubo Cardiomyopathy. Circulation. 2012; 126(6): 697-706. PMid:22732314. https://doi .org/10.1161/CIRCULATIONAHA .112.111591

[4] Demea AD, Dunca DG, Radu RA, et al. Takotsubo Syndrome Induced By Malignant PheochromocytomaIn A Patient With Type 2 Papillary Renal Cell Carcinoma - A Case Report. Clujul Medical. 2018. PMid:29785166.

[5] Cecconi A, Franco E, Agustín JAD, et al. Hyponatremia-induced stress cardiomyopathy due to psychogenic polydipsia. International Journal of Cardiology. 2016; 202: 618-620. PMid:26447674. https : //doi.org/10.1016/j.ijcard.2015.09.123

[6] Patnaik S, Punjabi C, Nathan R, et al. Bland and broken hearted: A case of hyponatremia induced Tako-tsubo cardiomyopathy. International Journal of Cardiology. 2015; 187: 267-271. PMid:25838229. https://doi.org/10.1016/j.ijcard.2015.03.272
[7] Stout BJ, Hoshide R, Vincent DS. Takotsubo Cardiomyopathy in the Setting of Acute Alcohol Withdrawal. Hawai'i Journal of Medicine \& Public Health. 2012; 71(7): 193-194. PMid:22787571.

[8] Omar HR, Abdelmalak HD, Komorova I, et al. Alcohol withdrawalinduced Takotsubo. Internal and Emergency Medicine. 2012; 7(2): 107-108. PMid:22441838. https://doi.org/10.1007/s11739 $-012-0766-0$

[9] Worthley MI, Anderson TJ. Transient left ventricular apical ballooning syndrome following a hyponatraemic seizure. Int J Cardiol. 2007; 115: e102-e104. PMid:17049651. https://doi.org/10.1016/j . ijcard.2006.07.091

[10] Lemke DM, Hussain SI, Wolfe TJ, et al. Takotsubo cardiomyopathy associated with seizures. Neurocrit Care. 2008; 9: 112117. PMid:18347760. https://doi.org/10.1007/s12028-008 $-9075-\mathrm{x}$

[11] Abou EO, Prasad A. Apical ballooning syndrome precipitated by hyponatremia. Int J Cardiol. 2010; 145: e26-e29. PMid:19195723. https://doi.org/10.1016/j.ijcard.2008.12.195

[12] Hiroaki K, Yuji M. Takotsubo Cardiomyopathy in a Patient with Severe Hyponatremia Associated with Syndrome of Inappropriate Antidiuretic Hormone. Intern Med. 2011; 50(7): 727-32. https : //doi.org/10.2169/internalmedicine.50.4795

[13] Cecconi A, Franco E, Agustín JA, et al. Hyponatremia-induced stress cardiomyopathy due to psychogenic polydipsia. International Journal of Cardiology. 2016; 202: 618-620. PMid:26447674. https : //doi.org/10.1016/j.ijcard.2015.09.123 